\title{
Vascular endothelial growth factor receptor inhibition enhances chronic obstructive pulmonary disease picture in mice exposed to waterpipe smoke
}

\author{
A. Alzoubi ${ }^{1}$, R. Ghazwi ${ }^{1}$, K. Alzoubi², M. Alqudah ${ }^{3}$, K. Kheirallah' ${ }^{4}$, O. Khabour ${ }^{5}$, M. Allouh ${ }^{6}$ \\ ${ }^{1}$ Department of Pharmacology, Faculty of Medicine, Jordan University of Science and Technology, Irbid, Jordan \\ ${ }^{2}$ Department of Clinical Pharmacy, Faculty of Pharmacy, Jordan University of Science and Technology, Irbid, Jordan \\ ${ }^{3}$ Department of Pathology, Faculty of Medicine, Jordan University of Science and Technology, Irbid, Jordan \\ ${ }^{4}$ Department of Public Health, Faculty of Medicine, Jordan University of Science and Technology, Irbid, Jordan \\ ${ }^{5}$ Department of Medical Laboratory Sciences, Faculty of Applied Medical Sciences, Jordan University of Science \\ and Technology, Irbid, Jordan \\ ${ }^{6}$ Department of Anatomy, Faculty of Medicine, Jordan University of Science and Technology, Irbid, Jordan
}

[Received: 22 October 2017; Accepted: 13 December 2017]

Background: Chronic obstructive pulmonary disease (COPD) is marked by destruction of alveolar architecture. Preclinical modelling for COPD is challenging. Chronic cigarette smoke exposure, the reference animal model of COPD, is time-inefficient, while exposure to waterpipe smoke (WPS), a surging smoking modality, was not fully tested for its histopathological pulmonary consequences. Since alveolar damage and pulmonary vascular endothelial dysfunction are integral to COPD pathology, lung histopathological effects of WPS were temporally evaluated, alone or in combination with vascular endothelial growth factor receptor (VEGFR) inhibition in mice.

Materials and methods: Mice were exposed to WPS, 3 hours/day, 5 days/week, for 1, 2, 3, or 4 months. Another group of mice was exposed to WPS for 1 month, while being subjected to injections with the VEGFR blocker Sugen5416 (SU, $20 \mathrm{mg} / \mathrm{kg}$ ) 3 times weekly. Control mice were exposed to fresh air in a matching inhalation chamber. Histopathological assessment of COPD was performed. Alveolar destructive index (DI) was counted as the percentage of abnormally enlarged alveoli with damaged septa per all alveoli counted. Mean linear intercept (MLI) was calculated as a measure of airspace enlargement.

Results: Exposure to WPS resulted in significant increases in alveolar DI and MLI only after 4 months. Lung inflammatory score was minimal across all time-points. Importantly, combination of WPS and SU resulted in significantly increased DI, $\mathrm{MLI}$, and inflammatory scores as early as 1 month post exposure.

Conclusions: Combined exposure to WPS and SU results in COPD picture, highlighting the role of pulmonary vascular endothelial dysfunction in the disease. (Folia Morphol 2018; 77, 3: 447-455)

Key words: vascular endothelial growth factor receptor, waterpipe smoke, chronic obstructive pulmonary disease, Sugen 5416

Address for correspondence: A. Alzoubi, MD, PhD, Department of Pharmacology, Faculty of Medicine, Jordan University of Science and Technology, P.O. Box: 3030, Irbid, Jordan 22110, tel: +962 (2) 7201000 ext. (23866), fax: +962 (0) 2 7095123, e-mail: aaalzoubi28@just.edu.jo 


\section{INTRODUCTION}

Chronic obstructive pulmonary disease (COPD) is characterised by progressive airflow limitation, frequently complicated by acute exacerbations [4]. Smoking is conceivably the principal cause of the disease [36]. COPD is projected to be the third leading cause of death and the fifth leading cause of disability globally by the year 2020, harbouring massive health and economic burdens worldwide [1]. The past few decades registered significant advancements in our understanding of the pathology of COPD. However, such basic knowledge was not clinically translated into novel biomarkers of disease progression and/or treatment modalities [7, 9].

The unfortunate gap in translational science in the field of COPD prognostics and therapeutics is largely attributed to the inadequacy of the available preclinical models of the disease, as they fail to recapitulate the major features of COPD in terms of pathology and natural history [45]. The reference animal model of COPD is the chronic cigarette smoke exposure in rodents. However, these animals do not develop the severe disabling disease seen in humans, as the major structural and functional consequences do not appear to progress after cessation of smoke exposure $[6,10]$. More importantly, rodents require several months of exposure to cigarettes to develop some of the basic features of mild-moderate COPD, highlighting the time and cost inefficiency of this model [46]. In this regard, the effect of waterpipe smoking, as a distinct modality of tobacco smoke exposure, was never examined, despite the well-documented differences in toxicant composition and effect between cigarettes and waterpipe [12, 34]. Recent reports have signified the alarming upsurge in the frequency of waterpipe smoking worldwide [28, 29], necessitating more focused research on its unidentified pulmonary consequences [14].

Historically, chronic airway inflammation that is injurious to pulmonary epithelial cells was placed in the core of COPD pathogenesis [25]. End-stage disease results also in increased pulmonary vascular resistance, pulmonary hypertension, and right heart failure $[2,3]$. In this classical schema, pulmonary vascular endothelial damage is seen secondary to the severe "primary" airway disease. However, recent reports have shown that several measures of the systemic and pulmonary micro- and macrovascular functions are impaired even in early-stage COPD [38]. Furthermore, modelling for pulmonary vascular diseases, via inhibition of the vascular endothelial growth fac- tor (VEGF) signalling, traditionally induces COPD-like lung pathology [19]. Interestingly, cigarette smoke exposure was found to interrupt VEGF signalling in rat lungs and in lungs of COPD patients [26].

Based on this background, the following research question was raised: does the combined and simultaneous exposure to chronic waterpipe smoke (WPS) and vascular endothelial dysfunction enhance the induction of COPD in animals? To answer this question, temporal evaluation of the histopathological effect of whole-body exposure to WPS in mice was firstly done. Subsequently, the histopathological effect of combined exposure to WPS and the VEGF receptor (VEGFR) blocker Sugen5416 (Semaxinib [SU]) was evaluated.

\section{MATERIALS AND METHODS}

All experimental procedures conformed to the National Research Council's Guide for the Care and Use of Laboratory Animals (1996, published by National Academy Press, USA) and were approved by the Institutional Animal Care and Use Committee at Jordan University of Science and Technology.

\section{Animals and experimental groups}

Six weeks-old naïve BALB/c mice, weighing around $25 \mathrm{~g}$ each, were used in this study. The animals were maintained in the animal care unit at $24 \pm 1^{\circ} \mathrm{C}$ with a 12:12 light/dark cycle. Apart from the exposure sessions, ear-tagged and labelled mice were caged in groups of 4 in plastic cages, and food and water were available ad libitum.

Seven experimental groups of mice were studied as follows:

- A - normal controls $(n=6)$ : mice were placed in the inhalation chamber and exposed to fresh air.

- B-E - WPS-exposed: mice were placed in the inhalation chamber and exposed to WPS 3 hours/ /day, 5 days/week, for 1 (B), 2 (C), 3 (D), or 4 (E) months ( $\mathrm{n}=6$ for each time point).

- F - WPS + SU-exposed $(n=8)$ : mice underwent the same protocol of WPS exposure for 1 month, while being subjected to subcutaneous injections of the VEGFR blocker SU $(20 \mathrm{mg} / \mathrm{kg}$, Cayman Chemical, USA) 3 times weekly, based on the dosing regimen we and others have reported previously $[2,11,42]$.

- G - SU alone $(n=4)$ : mice were injected with SU $(20 \mathrm{mg} / \mathrm{kg}) 3$ times weekly for 1 month and exposed to fresh air in the inhalation chamber. 
The inhalation chamber and WPS

\section{exposure machine}

The inhalation chamber used in this study was described in full details by our group previously [22]. Briefly, the chamber, constructed from transparent polycarbonate, had a removable ceiling fitted with flow ports for: the WPS inlet, fresh air inlet, excess flow outlet, and smoke sampling line. A fan was suspended from the lid to ensure that the chamber contents are well-mixed during each exposure session. Carbon monoxide (CO) concentration was continuously monitored in the chamber using an electrochemical sensor (Bacharach Monoxor II, USA), drawing a flow rate of $0.3 \mathrm{LPM}$ through a $47 \mathrm{~mm}$ glass fibre filter (Pall Type A/E). Mean \pm standard deviation (SD) CO concentration across all exposure sessions was found to be $963 \pm 71$ ppm. Fresh air was continuously pumped into the chamber, for an estimated air change rate of approximately 1.5 changes per hour.

The WPS machine hooked to the chamber was a commercially available waterpipe machine that burns commercial flavoured tobacco (two-apple ma'assel), and utilises a variable flow positive displacement diaphragm pump to draw from a waterpipe and discharge into the inhalation chamber applying a whole-body exposure to smoke. Generally, the smoke from the waterpipe passes first through the water before it is drawn into the inhalation chamber. Water was replaced before each exposure session. The pump was automatically controlled to provide 171 puffs of $2.6 \mathrm{~s}$ duration with an inter-puff interval of $17 \mathrm{~s}$, in accordance with the Beirut Method [21]. During each exposure session, puff volumes were monitored and recorded using a waterpipe puff topography instrument, simulating the human puff topography during waterpipe smoking, as reported previously [39].

\section{Lung inflation and fixation}

At the end of experimental periods, mice were sacrificed $12 \mathrm{~h}$ after the last WPS exposure session, with an overdose of pentobarbital administered intraperitoneally. Mice were then placed on a surgical pad, and an open chest procedure was performed, where lungs were dissected out. Isolated lungs were fixed for histological analysis by tracheal instillation of a mixture of $1 \%$ formalin and $0.5 \%$ agarose under constant pressure $\left(20 \mathrm{cmH}_{2} \mathrm{O}\right)$. The trachea was ligated after sustained inflation, and the lung was then immersed in $10 \%$ formalin for $48 \mathrm{~h}$. Formalin-fixed lung samples were subsequently cut into $5 \mathrm{~mm}$-thick sections, placed in $70 \%$ ethanol, and embedded in paraffin. Paraffin sections ( $5 \mu \mathrm{m}$ thick) were then serially mounted onto slides and stained with haematoxylin and eosin (H\&E) and Periodic acid-Schiff (PAS) stains.

\section{Histopathological analyses of lung samples}

Mean linear intercept. Mean linear intercept (MLI) in lung samples, a measure of airspace enlargement, was examined on two full sections of each lung, as previously reported [35]. Using light microscopy, MLI was determined on a transparent overlay consisting of 10 horizontal and 10 vertical lines superimposed over H\&E stained slides (Fig. 1A). All intercepts with alveolar septal walls were counted at the intersection point of the two lines. The total length of all the lines together divided by the total number of intercepts gives the MLI for the region studied.

Destructive index. Destructive index (DI), a gauge of parenchymal destruction [37], was evaluated by a microscopic point count technique, using a transparent sheet with 100 counting points laid on microscopic images of H\&E stained lungs by three blinded observers (Fig. 1B). Two full sections of each lung were evaluated. Regions containing large bronchi, vessels, collapsed tissue, or extensive fibrosis were excluded from counting. Destruction was defined as the presence of classic emphysematous changes in the form of abnormal enlargement of airspaces distal to the terminal bronchioles with destruction of the alveolar septa. DI was calculated as the percentage of destroyed alveoli of all the alveoli counted per section.

Inflammatory infiltration. Scoring of lung inflammatory cell infiltration was performed using the system developed for the assessment of inflammation in pulmonary hypertension by Stacher et al. [41], with some modifications (Fig. 2A). Briefly, the parenchymal infiltrate surrounding each large airway was quantified as 0 - absent; 1 - minimal with a single layer clustering of inflammatory cells; 2 - moderate, with localised clustering of inflammatory cells; and, 3 abundant, with large clusters of inflammatory cells extending from the airway towards adjacent alveoli. Two full sections were examined per each lung by three blinded observers. The final inflammatory score was the result of: $\left[0^{*} n\right.$ airways with 0 score $+1^{*} n$ airways with 1 score, $2^{*} n$ airways with 2 score $+3{ }^{*} n$ airways with 3 score]/number of analysed airways.

Mucus hypersecretion. Lung samples were stained with PAS stain for the assessment of mucus 
A

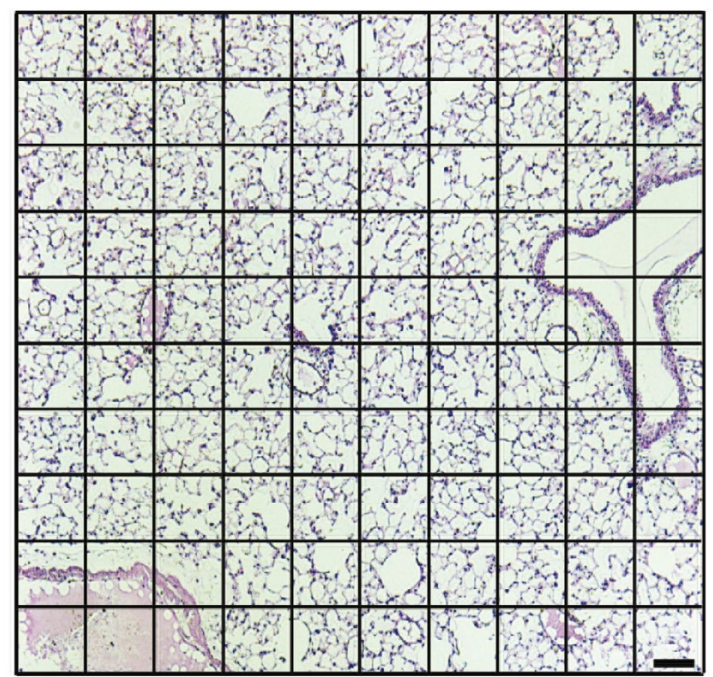

B

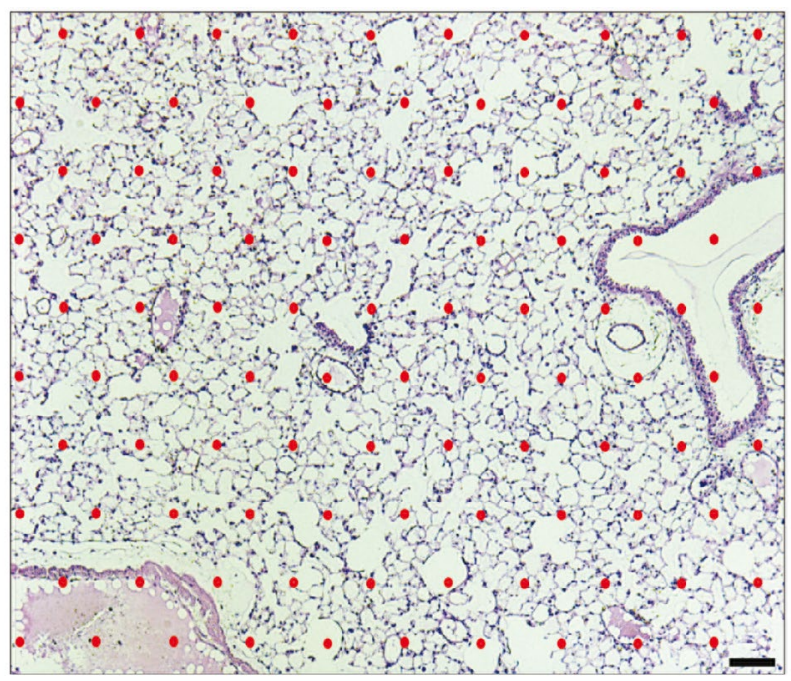

Figure 1. Mean linear intercept (MLI) and destructive index (DI). A. MLI was calculated by dividing the total length of all superimposed lines by the total number of intercepts with alveolar septal walls at the intersection point of two horizontal and vertical lines. B. DI was given as the percentage of destroyed alveoli of all the alveoli counted per section, using a microscopic point count technique. Scale bar $=100 \mu \mathrm{m}$.

A

Score 0

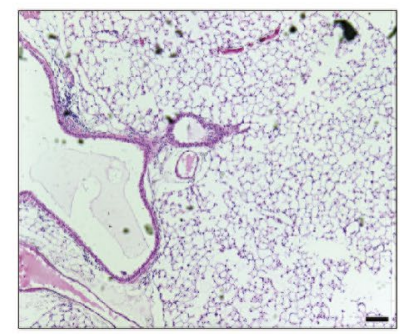

Score 2

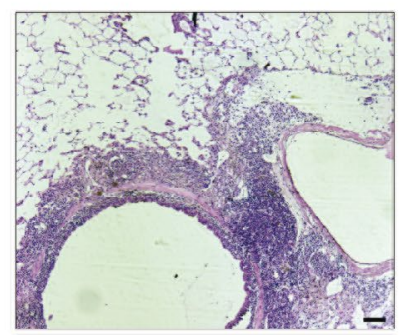

Score 1

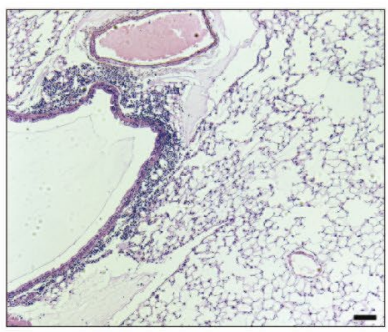

Score 3

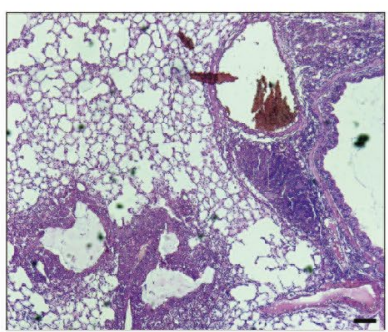

B
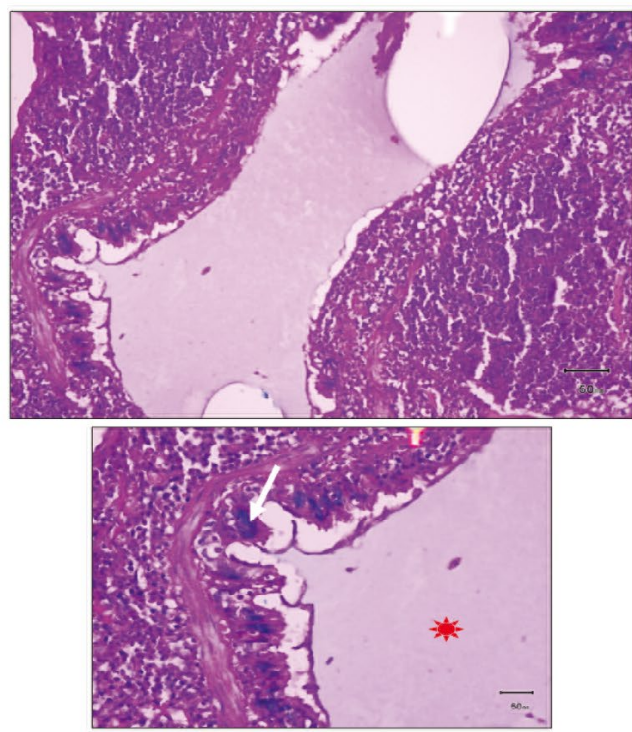

Figure 2. Inflammatory score and mucus index. A. Inflammatory infiltration was scored as 0 - absent, 1 - minimal, with a single layer clustering of inflammatory cells; 2 - moderate, with localized clustering of inflammatory cells; and, 3 - abundant, with large clusters of inflammatory cells. Scale bar $=100 \mu \mathrm{m}$. B. Mucus index was evaluated by Periodic acid-Schiff (PAS) stain, where mucus stains light purple (red asterisk) and the cellular/glandular source stains blue (white arrow). Scale bar $=50 \mu \mathrm{m}$.

hypersecretion. Mucus index (Fig. 2B) was developed to indicate the number of large airways positive for mucus (light purple colour) provided that the same airway showed positive staining for a cellular/glandular source of mucus (blue colour). Two full sections were examined per each lung by three blinded observers.

\section{Statistical analysis}

Values shown are means \pm standard error of mean. Paired Student t-test was used for comparison of mice body weights before and after experimental exposures. Analysis of variance (ANOVA) with Bonferroni post hoc test was used for comparisons among the experimental groups (time points). Differ- 
Table 1. Mean body weights ( \pm standard error of mean) of mice at baseline and at the end of experimental exposure

\begin{tabular}{lccc}
\hline Experimental group & Weight at baseline [g] & Weight after [g] & Probability \\
\hline A-Control & $26.6 \pm 1.5$ & - & - \\
B-1 month WPS & $26.2 \pm 1.1$ & $25.3 \pm 1$ & $\mathrm{p}=0.01$ \\
C-2 months WPS & $27.3 \pm 1.4$ & $24.9 \pm 1.1$ & $\mathrm{p}=0.3$ \\
D-3 months WPS & $26.0 \pm 1.7$ & $25.1 \pm 1.1$ & $\mathrm{p}=0.6$ \\
E-4 months WPS & $27.2 \pm 1.4$ & $26.2 \pm 1.7$ & $\mathrm{p}=0.6$ \\
F-WPS + SU & $27.6 \pm 0.7$ & $24.2 \pm 0.7$ & $\mathrm{p}=0.0008$ \\
G-SU alone & $28.5 \pm 0.5$ & $25.8 \pm 0.5$ & $\mathrm{p}=0.007$ \\
\hline
\end{tabular}

SU — Semaxinib; WPS — waterpipe smoke

ences were considered significant at $p<0.05$. Data were analysed using the GraphPad Prism 5 software (GraphPad Software, Inc., USA).

\section{RESULTS}

Chronic WPS exposure leads to progressive loss of normal lung architecture devoid of substantial parenchymal inflammation

All mice survived the experimental exposures to WPS alone or in combination with SU. However, mean body weights of mice were generally lower at the end of experimental exposures in groups B through $\mathrm{G}$ (Table 1). A general overview of the resulting lung histological phenotype in the 7 experimental groups is shown in Figure 3. Chronic WPS exposure leads to progressive enlargement of airspaces, as assessed by MLI, culminating in a statistically significant increase at the 4-month time point (Fig. 4A). Furthermore, chronic WPS resulted in a time-dependent loss of normal alveolar architecture, as evaluated by the DI, reaching marked levels of destruction after 4 months of exposure (Fig. 4C). Contrary to the pathological picture of COPD in humans, lung interstitial inflammatory cell infiltration was minimal across all time points of chronic WPS exposure (Fig. 4E). Moreover, we sought to determine the presence of bronchial mucus, and if so the source of that mucus, in this mouse model, using the PAS stain. Mucus index, as given by the number of large airways positive for mucus and its cellular/glandular source, revealed no significant changes over time (Fig. 4G), perhaps highlighting the well-documented finding that rodents lack, or perhaps more accurately have much less numbers of, goblet cells and bronchial glands [16].

The combined exposure to chronic WPS and SU recapitulates major histopathological features of COPD

The simultaneous exposure to chronic WPS and SU for 1 month caused significant increases in both the MLI (Fig. 4B) and DI (Fig. 4D) compared to controls.
These pathological changes were not observed in the SU alone group. Intriguingly, such morphometric changes were comparable in magnitude to those observed after 4 months of exposure to WPS alone. However, both SU alone and the combined use of WPS and SU for 1 month induced severe lung parenchymal inflammation (Fig. 4F), indicating an additional phenotypic advantage over the use of chronic WPS alone as a preclinical model of COPD. The mucus index, nevertheless, remained consistently similar to those found across all time points of chronic WPS exposure (Fig. 4H).

\section{DISCUSSION}

This study preliminarily reports the successful induction of COPD histopathological picture in mice by the combined and simultaneous exposure to WPS and the VEGFR blocker, SU. This novel preclinical model of COPD is primarily time and cost efficient, and exhibits major histopathological features of COPD, including airspace enlargement, destruction of alveolar structure, and marked parenchymal inflammation. Furthermore, this study supported the hypothesis that pulmonary vascular endothelial dysfunction critically drives the onset of COPD, and works together with alveolar epithelial loss throughout the progression of the disease.

The term "COPD" encompasses a group of diseases that have in common a state of progressive airflow limitation, caused by the airways' enhanced inflammatory responses to noxious stimuli [18]. Pathologically, COPD is marked by chronic inflammatory cell infiltration and pro-inflammatory mediators that lead to pulmonary epithelial cell death/apoptosis, and hence small airway remodelling and loss of alveoli [17]. Despite such basic knowledge, accumulating evidence proved that none of the available therapies of COPD stops the ultimate fatal drop in lung function. It is possible, therefore, that exploring new dimen- 

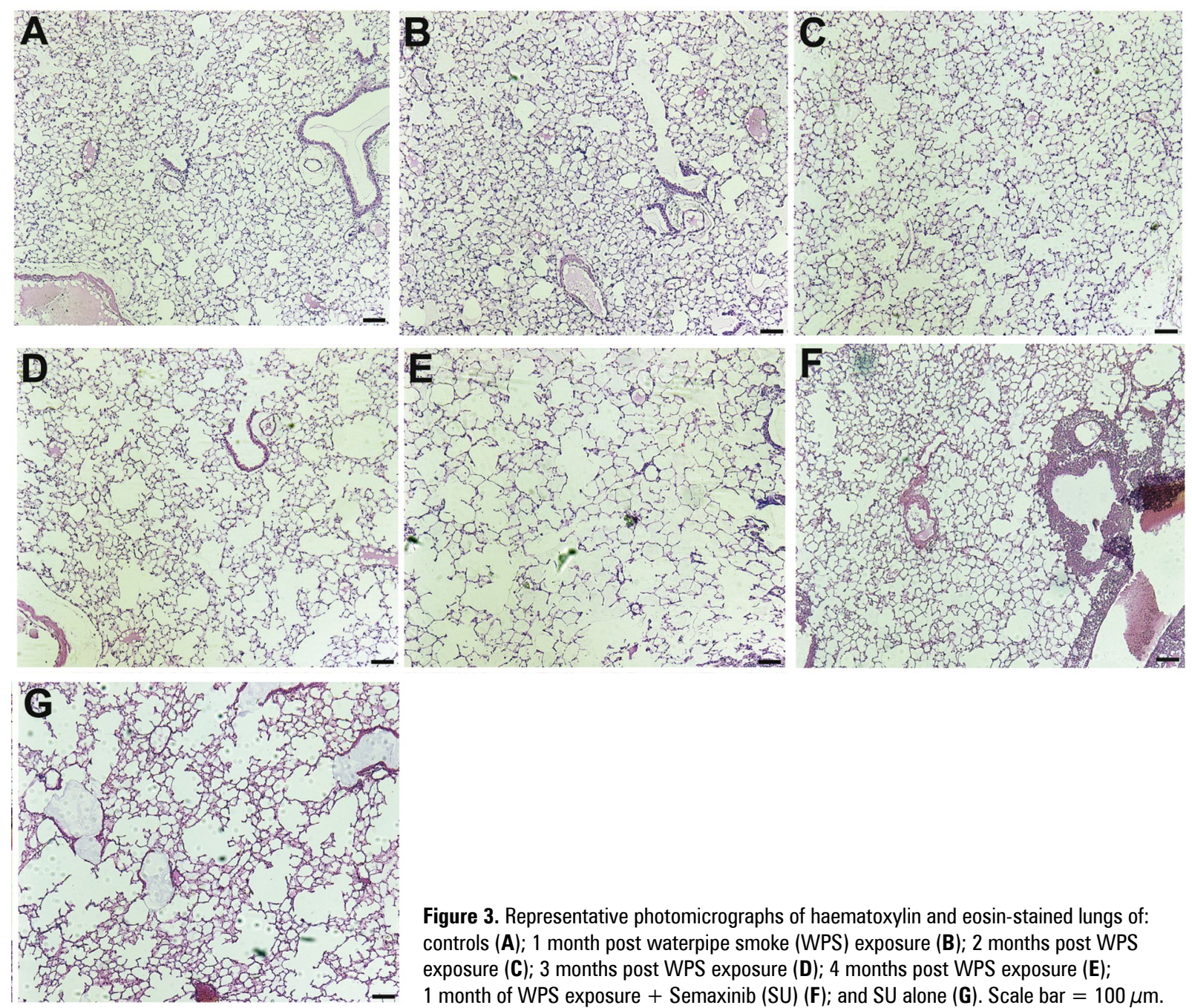

Figure 3. Representative photomicrographs of haematoxylin and eosin-stained lungs of: controls (A); 1 month post waterpipe smoke (WPS) exposure (B); 2 months post WPS exposure (C); 3 months post WPS exposure (D); 4 months post WPS exposure (E); 1 month of WPS exposure + Semaxinib (SU) (F); and SU alone (G). Scale bar $=100 \mu \mathrm{m}$.

sions in the pathology of COPD would offer insightful prognostic and therapeutic targets [8].

The Global Initiative for Chronic Obstructive Lung Disease (GOLD) lists COPD as a preventable and treatable disease, despite being often complicated by exacerbations that worsen the patients' outcome [15]. The "preventable" part of the definition pertains to the fact that smoking is the principal causative factor in COPD. Chronic WPS exposure was utilised as the source of tobacco smoke in this study. Waterpipe smoking is a predominant tobacco delivery method in both developed and developing countries. There is a cultural acceptance of waterpipe smoking, based on the misperception of its safety and lack of long-term health hazards, particularly cancers and respiratory problems [23]. Waterpipe smoking is now considered the second most popular method of tobacco smoking in many developed countries [30], while surpassing cigarette smoking in 19 out of 24 countries in the Eastern Mediterranean Region [23].
These high rates testify to the pervasiveness of the problem around the world. Importantly, several studies showed that the exposure pattern and dose of various components of tobacco smoke are very different between waterpipe and cigarette smoking [27, 34]. For instance, relative to 1 cigarette, a single session of waterpipe involves inhaling 60-160 times smoke volume, 1.7-2.3 times nicotine, 25-46 times tar, and 5-10 times CO $[12,40]$. Despite such considerable differences, the long-term pulmonary consequences have not been fully elucidated. Thus, the current results can be of major clinical significance, as they underscore waterpipe smoking as a potential risk for the development of COPD.

The role of endothelial dysfunction in COPD pathology was also explored in this study, based on the substantial evidence that changes in the endothelial milieu occur early in the disease process. Dinh-Xuan et al.; 1991 [13], Peinado et al.; 1998 [32], Komurcuoglu et al.; 2003 [24], and Barr et al.; 2007 [5] have all reported increased 
A
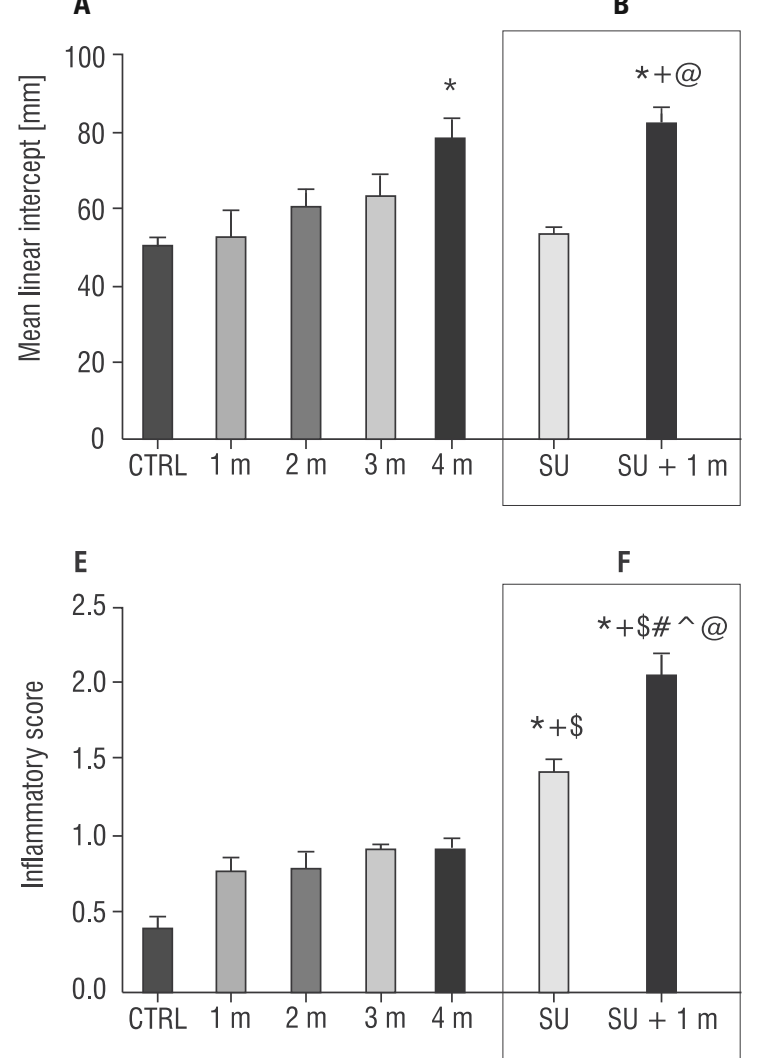

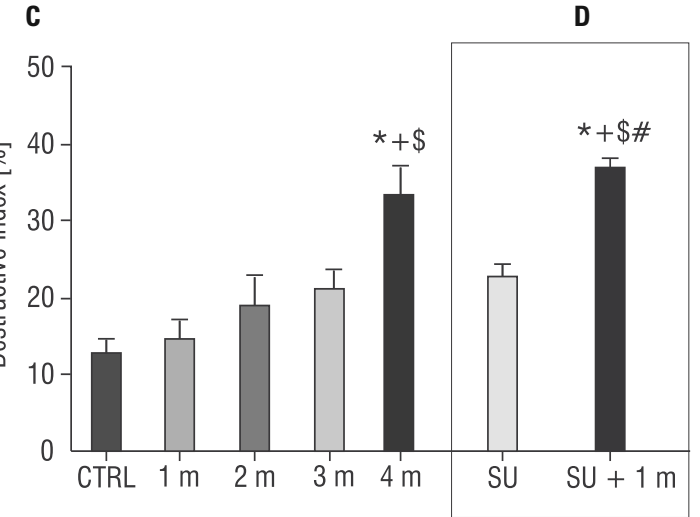

G

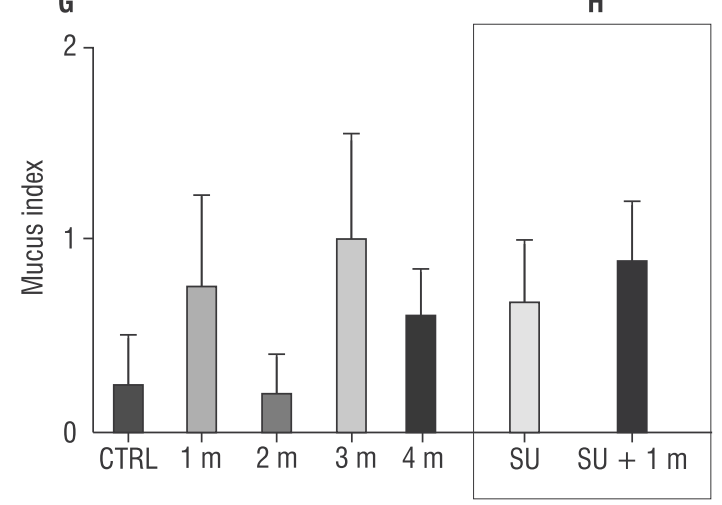

Figure 4. A, B. Mean linear intercept; C, D. Destructive index; E, F. Inflammatory score; G, H. Mucus index in the seven experimental groups. ${ }^{*} p<0.05$ vs. controls; $+p<0.05$ vs. 1 month post waterpipe smoke (WPS); $\$ p<0.05$ vs. 2 months post WPS; \#p $<0.05$ vs. 3 months post WPS; $\wedge p<0.05$ vs. 4 months post WPS; @ $<<0.05$ vs. Semaxinib (SU) alone; $m$ - month; CTRL — control.

markers of systemic endothelial dysfunction in mild COPD cases. These markers included microalbuminuria, impaired flow-mediated dilation, and decreased retinal vessel calibre. Kasahara et al. (2001) [20] reported that emphysematous lungs exhibit significant endothelial cell death and decreased expression of VEGF and VEGFR. Santos et al. (2003) [38] have also shown increased expression of VEGF in the pulmonary arteries of smokers with mild COPD. Additionally, Polatli et al. (2008) [33] reported that COPD patients displayed microalbuminuria and increased plasma levels of the von Willibrand factor and fibrinogen during exacerbations. Such considerable evidence of involvement of endothelial dysfunction in COPD is the pivotal rationale for our study.

The use of SU as an inducer of endothelial dysfunction in the current model builds on the previous report by Kasahara et al. (2000) [19], as they reported that SU injection in "healthy" rats causes alveolar cell apoptosis, emphysema, and pruning of the pulmonary arterial tree. VEGF, the chief member of hypoxia-inducible factor genes, is highly expressed in the lungs, and has been historically recognised as a "vascular permeability factor"
[44]. Its major functions include: vascular endothelial cell growth and differentiation, vessel morphogenesis, and regulation of endothelial cell survival. VEGF also regulates growth and differentiation of type II pneumocytes, pointing to its critical role in the maintenance of "alveolar unit" normal functionality [43]. Blockade of such vital functions by SU could add to the alveolar damage induced by WPS exposure, enhancing the induction of a COPD picture, most notably by stimulating lung inflammatory cell infiltration, as reported by Otsuki et al. [31].

This study manifests several limitations. While some of the major histopathological features of COPD were investigated, we have not elucidated the impact of these changes on lung mechanics and dynamics. This has hindered the grading/staging of COPD in this model according to the GOLD criteria, which largely depend on pulmonary function tests in assessing severity of COPD in patients [15]. We have not explored any markers of pulmonary or systemic endothelial dysfunction in this model. Additionally, the current sample size of animals used in this study is too small for a meaningful translation into a human risk assessment. However, we anticipate this report will open 
the door for further studies in the biomarkers research field. When correlated with the severity and outcomes of COPD, such biomarkers will be of significant diagnostic, prognostic, and therapeutic value in the future.

\section{CONCLUSIONS}

In conclusion, the combined exposure to chronic WPS and SU is a time and cost effective approach to preclinical modelling of COPD. The current results support the hypothesis that pulmonary vascular endothelial dysfunction critically drives the onset of COPD, and works together with alveolar epithelial loss throughout the progression of the disease.

\section{Acknowledgements and funding}

The authors wish to thank Dr. Kohtaro Abe (Fukuoka University, Japan) for his generous contribution to this project by providing the drug SU5416 used in the study, and to Dr. Mohammad Abdallah and Ms. Raba'a Athamneh for their technical assistance during WPS exposure experiments.

This work was supported by a grant from the Deanship of Research at Jordan University of Science and Technology (254/2014).

\section{REFERENCES}

1. Adeloye D, Chua S, Lee C, et al. Global Health Epidemiology Reference Group (GHERG). Global and regional estimates of COPD prevalence: Systematic review and meta-analysis. J Glob Health. 2015; 5(2): 020415, doi: 10.7189/jogh.05020415, indexed in Pubmed: 26755942.

2. Alzoubi A, Toba M, Abe K, et al. Dehydroepiandrosterone restores right ventricular structure and function in rats with severe pulmonary arterial hypertension. Am J Physiol Heart Circ Physiol. 2013; 304(12): H1708-H1718, doi: 10.1152/ ajpheart.00746.2012, indexed in Pubmed: 23585128.

3. Barberà JA, Peinado VI, Santos S. Pulmonary hypertension in chronic obstructive pulmonary disease. Eur Resp J. 2003; 21(5): 892-905, doi: 10.1183/09031936.03.00115402.

4. Barnes PJ. Chronic obstructive pulmonary disease. N Engl J Med. 2000; 343(4): 269-280, doi: 10.1056/ NEJM200007273430407, indexed in Pubmed: 10911010.

5. Barr RG, Mesia-Vela S, Austin JHM, et al. Impaired flowmediated dilation is associated with low pulmonary function and emphysema in ex-smokers: the Emphysema and Cancer Action Project (EMCAP) Study. Am J Respir Crit Care Med. 2007; 176(12): 1200-1207, doi: 10.1164/rccm.2007079800C, indexed in Pubmed: 17761614.

6. Bartalesi B, Cavarra E, Fineschi S, et al. Different lung responses to cigarette smoke in two strains of mice sensitive to oxidants. Eur Respir J. 2005; 25(1): 15-22, doi: 10.1183 /09031936.04.00067204, indexed in Pubmed: 15640318.

7. Beasley R, Weatherall $M$, Travers J, et al. Time to define the disorders of the syndrome of COPD. Lancet. 2009; 374(9691): 670-672, doi: 10.1016/S0140-6736(09)61541-5, indexed in Pubmed: 19716947.
8. Celli BR, Thomas NE, Anderson JA, et al. Effect of pharmacotherapy on rate of decline of lung function in chronic obstructive pulmonary disease: results from the TORCH study. Am J Respir Crit Care Med. 2008; 178(4): 332-338, doi: 10.1164/ rccm.200712-18690C, indexed in Pubmed: 18511702.

9. Celli BR, Decramer M, Wedzicha JA, et al. An Official American Thoracic Society/European Respiratory Society Statement: Research questions in chronic obstructive pulmonary disease. Am J Respir Crit Care Med. 2015; 191(7): e4-ee27, doi: 10.1164/rccm.201501-0044ST, indexed in Pubmed: 25830527.

10. Churg A, Cosio M, Wright JL. Mechanisms of cigarette smoke-induced COPD: insights from animal models. Am J Physiol Lung Cell Mol Physiol. 2008; 294(4): L612-L631, doi: 10.1152/ajplung.00390.2007, indexed in Pubmed: 18223159 .

11. Ciuclan L, Bonneau O, Hussey M, et al. A novel murine model of severe pulmonary arterial hypertension. Am J Respir Crit Care Med. 2011; 184(10): 1171-1182, doi: 10.1164/ rccm.201103-04120C, indexed in Pubmed: 21868504.

12. Cobb CO, Shihadeh A, Weaver MF, et al. Waterpipe tobacco smoking and cigarette smoking: a direct comparison of toxicant exposure and subjective effects. Nicotine Tob Res. 2011; 13(2): 78-87, doi: $10.1093 /$ ntr/ntq212, indexed in Pubmed: 21127030.

13. Dinh-Xuan AT, Higenbottam TW, Clelland CA, et al. Impairment of endothelium-dependent pulmonary-artery relaxation in chronic obstructive lung disease. N Engl J Med. 1991; 324(22): 1539-1547, doi: 10.1056/NEJM199105303242203, indexed in Pubmed: 2027358.

14. El-Zaatari ZM, Chami HA, Zaatari GS. Health effects associated with waterpipe smoking. Tob Control. 2015; 24 Suppl 1: i31-i43, doi: 10.1136/tobaccocontrol-2014-051908, indexed in Pubmed: 25661414.

15. Fabbri LM, Hurd SS. Global Strategy for the Diagnosis, Management and Prevention of COPD: 2003 update. Eur Respir J. 2003; 22(1): 1-2, doi: 10.1183/09031936.03.00063703.

16. GoCo R, Kress M, Brantigan O. Comparison of mucus glands in the tracheobronchial tree of man and animals*. Ann N Y Acad Sci. 2008; 106(2): 555-571, doi: 10.1111/j.17496632.1963.tb16665.x.

17. Hogg JC. Pathophysiology of airflow limitation in chronic obstructive pulmonary disease. Lancet. 2004; 364(9435): 709-721, doi: 10.1016/\$0140-6736(04)16900-6, indexed in Pubmed: 15325838.

18. Hogg JC, Chu F, Utokaparch S, et al. The nature of smallairway obstruction in chronic obstructive pulmonary disease. N Engl J Med. 2004; 350(26): 2645-2653, doi: 10.1056/ NEJMoa032158, indexed in Pubmed: 15215480.

19. Kasahara Y, Tuder RM, Taraseviciene-Stewart L, et al. Inhibition of VEGF receptors causes lung cell apoptosis and emphysema. J Clin Invest. 2000; 106(11): 1311-1319, doi: 10.1172/ JCl10259, indexed in Pubmed: 11104784.

20. Kasahara Y, Tuder RM, Cool CD, et al. Endothelial cell death and decreased expression of vascular endothelial growth factor and vascular endothelial growth factor receptor 2 in emphysema. Am J Respir Crit Care Med. 2001; 163(3 Pt 1): 737-744, doi: 10.1164/ajrccm.163.3.2002117, indexed in Pubmed: 11254533.

21. Katurji M, Daher N, Sheheitli $H$, et al. Direct measurement of toxicants inhaled by water pipe users in the natural environment using a real-time in situ sampling technique. Inhal 
Toxicol. 2010; 22(13): 1101-1109, doi: 10.3109/08958378. 2010.524265, indexed in Pubmed: 21062108.

22. Khabour OF, Alzoubi KH, Bani-Ahmad M, et al. Acute exposure to waterpipe tobacco smoke induces changes in the oxidative and inflammatory markers in mouse lung. Inhal Toxicol. 2012; 24(10): 667-675, doi: 10.3109/08958378.20 12.710918, indexed in Pubmed: 22906173.

23. Kheirallah KA, Alsulaiman JW, Mohammad H AS, et al. Waterpipe Tobacco Smoking among Arab Youth; a Cross-Country Study. Ethn Dis. 2016; 26(1): 107-112, doi: 10.18865/ ed.26.1.107, indexed in Pubmed: 26843803.

24. Komurcuoglu A, Kalenci S, Kalenci D. Microalbuminuria in chronic obstructive pulmonary disease. Monaldi Arch Chest Dis. 2003; 59(4): 269-272, indexed in Pubmed: 15148835.

25. Macleod $\sqcup$, Heard BE. Area of muscle in tracheal sections in chronic bronchitis, measured by point-counting. J Pathol. 1969; 97(1): 157-161, doi: 10.1002/path.1710970124, indexed in Pubmed: 5783633.

26. Marwick JA, Stevenson CS, Giddings J, et al. Cigarette smoke disrupts VEGF165-VEGFR-2 receptor signaling complex in rat lungs and patients with COPD: morphological impact of VEGFR-2 inhibition. Am J Physiol Lung Cell Mol Physiol. 2006; 290(5): L897-L908, doi: 10.1152/ajplung.00116.2005, indexed in Pubmed: 16361360.

27. Maziak W, Rastam S, Ibrahim I, et al. CO exposure, puff topography, and subjective effects in waterpipe tobacco smokers. Nicotine Tob Res. 2009; 11(7): 806-811, doi: 10.1093/ ntr/ntp066, indexed in Pubmed: 19420278.

28. Maziak W. The global epidemic of waterpipe smoking. Addict Behav. 2011; 36(1-2): 1-5, doi: 10.1016/j.addbeh.2010.08.030, indexed in Pubmed: 20888700.

29. Maziak W. The waterpipe: a new way of hooking youth on tobacco. Am J Addict. 2014; 23(2): 103-107, doi: 10.1111/j.1521-0391.2013.12073.x, indexed in Pubmed: 25187045.

30. Maziak W, Taleb ZB, Bahelah R, et al. The global epidemiology of waterpipe smoking. Tob Control. 2015; 24 Suppl 1: i3-ii12, doi: 10.1136/tobaccocontrol-2014-051903, indexed in Pubmed: 25298368.

31. Otsuki S, Sawada H, Yodoya N, et al. Potential contribution of phenotypically modulated smooth muscle cells and related inflammation in the development of experimental obstructive pulmonary vasculopathy in rats. PLoS One. 2015; 10(2): e0118655, doi: 10.1371/journal.pone.0118655, indexed in Pubmed: 25714834.

32. Peinado VI, Barbera JA, Ramirez J, et al. Endothelial dysfunction in pulmonary arteries of patients with mild COPD. Am J Physiol. 1998; 274(6 Pt 1): L908-L913, indexed in Pubmed: 9609729.

33. Polatli M, Cakir A, Cildag O, et al. Microalbuminuria, von Willebrand factor and fibrinogen levels as markers of the severity in COPD exacerbation. J Thromb Thrombolysis. 2008; 26(2): 97-102, doi: 10.1007/s11239-007-0073-1, indexed in Pubmed: 17622488.

34. Primack BA, Carroll MV, Weiss PM, et al. Systematic review and meta-analysis of inhaled toxicants from waterpipe and cigarette smoking. Public Health Rep. 2016; 131(1): 76-85, doi: 10.1177/003335491613100114, indexed in Pubmed: 26843673

35. Robbesom AA, Versteeg EMM, Veerkamp JH, et al. Morphological quantification of emphysema in small human lung specimens: comparison of methods and relation with clinical data. Mod Pathol. 2003; 16(1): 1-7, doi: 10.1097/01. MP.0000043519.29370.C2, indexed in Pubmed: 12527706.

36. Rosenberg SR, Kalhan R, Mannino DM. Epidemiology of chronic obstructive pulmonary disease: prevalence, morbidity, mortality, and risk factors. Semin Respir Crit Care Med. 2015; 36(4): 457-469, doi: 10.1055/s-0035-1555607, indexed in Pubmed: 26238634.

37. Saetta M, Shiner RJ, Angus GE, et al. Destructive index: a measurement of lung parenchymal destruction in smokers. Am Rev Respir Dis. 1985; 131(5): 764-769, doi: 10.1164/ arrd.1985.131.5.764, indexed in Pubmed: 4003921.

38. Santos S, Peinado VI, Ramirez J, et al. Enhanced expression of vascular endothelial growth factor in pulmonary arteries of smokers and patients with moderate chronic obstructive pulmonary disease. Am J Respir Crit Care Med. 2003; 167(9): 1250-1256, doi: 10.1164/rccm.200210-12330C, indexed in Pubmed: 12615615.

39. Shihadeh A, Azar S, Antonios C, et al. Towards a topographical model of narghile water-pipe café smoking: a pilot study in a high socioeconomic status neighborhood of Beirut, Lebanon. Pharmacol Biochem Behav. 2004; 79(1): 75-82, doi: 10.1016/j. pbb.2004.06.005, indexed in Pubmed: 15388286.

40. Singh S, Soumya M, Saini A, et al. Breath carbon monoxide levels in different forms of smoking. Indian J Chest Dis Allied Sci. 2011; 53(1): 25-28, indexed in Pubmed: 21446221.

41. Stacher E, Graham BB, Hunt JM, et al. Modern age pathology of pulmonary arterial hypertension. Am J Respir Crit Care Med. 2012; 186(3): 261-272, doi: 10.1164/rccm.20120101640C, indexed in Pubmed: 22679007.

42. Toba M, Alzoubi A, O'Neill KD, et al. Temporal hemodynamic and histological progression in Sugen5416/hypoxia/normoxia-exposed pulmonary arterial hypertensive rats. Am J Physiol Heart Circ Physiol. 2014; 306(2): H243-H250, doi: 10.1152/ ajpheart.00728.2013, indexed in Pubmed: 24240870.

43. Voelkel N, Cool C, Taraceviene-Stewart L, et al. Janus face of vascular endothelial growth factor: The obligatory survival factor for lung vascular endothelium controls precapillary artery remodeling in severe pulmonary hypertension. Crit Care Med. 2002; 30(5 Suppl): S251-S256, doi: 10.1097/00003246-200205001-00013.

44. Voelkel NF, Vandivier RW, Tuder RM. Vascular endothelial growth factor in the lung. Am J Physiol Lung Cell Mol Physiol. 2006; 290(2): L209-L221, doi: 10.1152/ajplung.00185.2005, indexed in Pubmed: 16403941.

45. Wright JL, Churg A. Animal models of COPD: Barriers, successes, and challenges. Pulm Pharmacol Ther. 2008; 21(5): 696-698, doi: 10.1016/j.pupt.2008.01.007, indexed in Pubmed: 18325803.

46. Wright JL, Cosio M, Churg A. Animal models of chronic obstructive pulmonary disease. Am J Physiol Lung Cell Mol Physiol. 2008; 295(1): L1-15, doi: 10.1152/ajplung.90200.2008, indexed in Pubmed: 18456796. 